\title{
LIBERDADE NUMA PERSPECTIVA DA PSICOLOGIA FENOMENOLÓGICO-EXISTENCIAL: REVISÃO SISTEMÁTICA DA PRODUÇÃO BIBLIOGRÁFICA DOS ÚLTIMOS VINTE ANOS
}

\author{
Freedom from an Existential Phenomenological Psychology Perspective: Systematic Review of \\ the Last Twenty Years Bibliographic Production
}

La Libertad en la Perspectiva de la Psicología Fenomenológico-Existencial: Revisión Sistemáti-
ca de la Producción Bibliográfica de los Últimos Veinte Años

\begin{abstract}
Resumo: A questão da liberdade permeia discussões nas ciências psicológicas, em especial na abordagem fenomenológico-existencial. O objetivo deste trabalho foi buscar compreender como a liberdade vem sendo estudada sob esta perspectiva. Para tal, foi realizada uma revisão sistemática de artigos publicados nos últimos vinte anos, nos idiomas português, inglês e espanhol. Foram consultadas as bases de dados virtuais Periódicos CAPES, PePSIC, SciELO e LILACS. Foram encontrados 954 artigos que passaram por seleção conforme critérios de inclusão, duplicidade e disponibilidade, totalizando 29 artigos para análise. Assim, foram consideradas as variáveis: ano de publicação, nacionalidade, área da revista, área dos autores, teóricos e filósofos de base, temáticas gerais dos artigos, forma de articulação com a Psicologia, termos atrelados à liberdade e a forma como os artigos conceituam liberdade. Evidenciou-se que a liberdade é tratada como característica fundamental do ser humano nas produções de base fenomenológico-existencial, porém com diferentes enfoques. Destacou-sea o caráter atual da discussão sobre liberdade, com maior número de produções datadas nos últimos 10 anos, e a predominância de artigos brasileiros sobre a temática.
\end{abstract}

Palavras-chave:Liberdade; Psicologia Existencial; Fenomenologia; Revisão Sistemática.

\begin{abstract}
Freedom as a subject of study permeates discussions in the psychological sciences, especially in the phenomenological-existential approach. The purpose of this study was to understand how freedom has been studied from this perspective. For this, a systematic review of articles published in the last twenty years in Portuguese, English and Spanish was carried out. The periodical databases CAPES, PePSIC, SciELO and LILACS were consulted. There were found 954 articles that were selected according to criteria of inclusion, duplicity and availability, totaling 29 articles for analysis. Thus, the following variables were considered: year of publication, nationality, area of the journal, area of the authors, theoretical and philosophical base, general topics, form of articulation with Psychology, terms linked to freedom and the way the articles conceptualize freedom. It has been shown that freedom is treated as a fundamental characteristic of the human being in productions based on phenomenological-existential perspective, but with different approaches. The current character of the discussion about freedom was highlighted, with a greater number of productions in the last 10 years, and the predominance of Brazilian articles on the subject.
\end{abstract}

Keywords: Freedom; Existential Psychology, Phenomenology, Systematic Review.

Resumen: La cuestión de la libertad está presente en las discusiones en las ciencias psicológicas, en especial en el enfoque fenomenológico-existencial. El objetivo de este trabajo fue buscar comprender cómo la libertad viene siendo estudiada bajo esta perspectiva. Para ello, se realizó una revisión sistemática de artículos publicados en los últimos veinte años, en los idiomas portugués, inglés y español. Se consultaron las bases de datos virtuales Periódicos CAPES, PePSIC, SciELO y LILACS. Fueron encontrados 954 artículos que pasaron por selección según criterios de inclusión, duplicidad y disponibilidad, totalizando 29 artículos para análisis. Así, fueron consideradas las variables: año de publicación, nacionalidad, área de la revista, área de los autores, teóricos y filósofos de base, temáticas generales de los artículos, forma de articulación con la Psicología, términos vinculados a la libertad y la forma como los artículos conceptuan libertad. Se evidenció que la libertad es tratada como característica fundamental del ser humano en las producciones de base fenomenológico-existencial, pero con diferentes enfoques. Se destacó el carácter actual de la discusión sobre libertad, con mayor número de producciones datadas en los últimos 10 años, y la predominancia de artículos brasileños sobre la temática.

Palabras-clave: Libertad; Psicología Existencial, Fenomenología, Revisión Sistemática. 


\section{Introdução}

Abordar a temática da liberdade é inevitável a qualquer ciência que pretenda aproximar-se do ser humano, seja numa perspectiva individual, relacional ou social. Na Psicologia, embora nem sempre seja discutido com profundidade, o conceito permeia as concepções de sujeito nas diferentes abordagens teóricas. Onde predominam ideias de causalidade linear e determinismo psíquico ou biológico, a liberdade não é tratada como uma característica fundamental do ser humano. Já no âmbito dos estudos em Psicologia publicados sobre o tema, a liberdade é referida, frequentemente, em seu sentido jurídico de privação de liberdade, como pesquisas envolvendo pessoas encarceradas (Castro \& Teodoro, 2014; Gomes \& Conceição, 2014; Castro \& Guareschi, 2008; Zappe, Santos, Ferrão \& Dias, 2013; Marques \& Ribeiro, 2013). Como May (1987) aponta, a liberdade sempre esteve historicamente significada como algo valioso, a ser conquistado e preservado, o que a coloca como um fenômeno separado e externo ao ser humano, além de imbuído de um valor unicamente positivo, já que é significada como a ausência de barreiras, limites ou prisões (Yalom, 1980).

Para as abordagens fenomenológicas e existenciais em Psicologia, a discussão acerca da liberdade toma diferentes rumos - e sentidos, se comparada a outras perspectivas teóricas em Psicologia. Segundo Teixeira (2006), a liberdade é um dos quatro dados da existência, junto à morte, à solidão e à falta de sentido, os quais seriam "fontes de ansiedade” (p.292) pelo seu caráter de inevitabilidade. O autor aponta que, embora teóricos da perspectiva existencial tenham dado ênfase a diferentes dados da existência, quase todos dão importância à negação da liberdade: "assim surgiu o conceito de inautenticidade, usado como sinônimo de auto-decepção por Heidegger e correspondendo ao conceito de má fé de Sartre” (p.292). É através desta perspectiva, mais dedicada as questões da existência humana, que este estudo buscará compreender os sentidos atribuídos à liberdade.

$\mathrm{O}$ interesse pelas questões existenciais atraiu filósofos, psiquiatras e psicanalistas no período entre as duas guerras mundiais e, principalmente, no pós-guerra. (Gomes \& Castro, 2010). A partir da publicação de Ser e tempo (1921) e dos Seminários de Zollikon (1959-1969) de Heidegger, o psiquiatra Ludwig Binswanger desenvolveu sua proposta clínica, a daseinsanálise, que teve continuidade e aprofundamento com Medard Boss, também psiquiatra. Constata-se, assim, que a clínica fenomenológico-existencial emergiu no campo da psiquiatria, onde havia forte tradição da psicanálise, porém, como Gomes e Castro (2010) apontam, a preocupação de psiquiatras como Binswanger e Boss era com outra conjuntura germinadora da doença mental que não as apontadas pela teoria freudiana.

Ao analisar as contribuições desses dois ex- poentes da daseinsanálise para a clínica, Moreira (2011) afirma que Binswanger, a partir de uma preocupação científica com a psiquiatria de sua época, buscou desenvolver sua análise existencial mais como um método de pesquisa do que como uma forma de psicoterapia. Daí o caráter mais elaborado de suas considerações acerca da psicopatologia em detrimento de teorizações acerca de uma proposta de tratamento. Por sua vez, Boss aproximou-se das ideias de Heidegger com preocupações de ordem da terapêutica, e segundo a autora, com tendência a um "pensamento que não permitia a colocação da distinção cartesiana sujeito-objeto e que, por outro lado, aproximava a medicina da psicologia” (p. 178). Constata-se, no trabalho desses dois autores, uma radical mudança ontológica e epistemológica do que predominava nos estudos em Psicologia na época, de uma visão objetificante de sujeito, para uma visão compreensiva do fenômeno psíquico.

Entretanto, é fundamental destacar que a tradição fenomenológico-existencial não se deriva apenas de um ou dois teóricos, pois

essa tradição não teve nas suas origens e na sua história um nome que agregasse as correntes e servisse de referência para a disputa nas várias interpretações teóricas. A abordagem foi desenvolvida por vários autores em diferentes países e os seguidores sempre foram livres para conduzirem a teoria e a prática conforme entendimento pessoal. (Gomes \& Castro, 2010, p. 87)

Quanto a esta multiplicidade de modos da compreensão e tratamento das questões existenciais, Teixeira (2006), na tentativa de fazer um apanhado das modalidades da psicoterapia existencial, apontou os principais pressupostos que seriam comuns a elas, que se referem à ênfase na dimensão histórica do sujeito, à ideia de projeto e à responsabilidade do sujeito na construção do seu mundo. A responsabilidade, principalmente, está irrevogavelmente atrelada à noção de liberdade (Yalom, 1980).

Na perspectiva fenomenológico-existencial, a liberdade é axiomática, é condição constitutiva do humano. Ela aparece atrelada ao caráter de indeterminação da existência que torna o homem responsável por aquilo que faz de si. Para Feijoo (2011), "tomar a existência como se constituindo pela indeterminação consiste em deslocar-se de qualquer tentativa de posicionar o homem a partir de determinações biológicas e sociais"(p.103). Outros "filósofos da existência", apesar de apresentarem grandes diferenças no campo epistemológico e conceitual, também apontam para a indeterminação como o caráter mais próximo do existir, como por exemplo como S. Kierkegaard, M. Heidegger e J. P. Sartre (Feijoo, 2011).

Atrelada à indeterminação da existência, a angústia é outro constructo que vem à tona quando o assunto é liberdade. Medard Boss, na sua concep- 
ção de angústia como algo intrínseco à existência humana, diz que se o ser humano estiver realmente aberto à essência verdadeira da angústia, ela abre ao ser a dimensão da liberdade, ou em outras palavras, à dimensão do Não-estar, do Nada, "mas daquele grande nada, que ao contrário do vazio da nulidade meramente niilista, abriga tudo dentro de si, e de tal forma que ele tanto pode encobrir como também desvelar-nos e desvelar as coisas do nosso mundo" (Boss, 1981, p.36). Se a existência humana é compreendida, na psicologia fenomenológico-existencial, como uma clareira da qual os fenômenos do mundo necessitam para poder aparecer e ser dentro dela, a liberdade do ser vem à tona justamente na possibilidade de corresponder ou de esquivar-se de tais reivindicações do mundo. Além da angústia, Boss (1981) ressalta que esse estar-solicitado por tudo que quer aparecer à luz da existência humana também é uma fonte de culpa, sendo que é impossível ao ser corresponder a todos os chamados. A escolha é inevitável e, seja ela qual for, é livre.

A dimensão do Nada, na qual reside a liberdade, também pode ser compreendida como uma falta de estrutura externa. Yalom (1980) explica que o ser humano não entra - e nem sai - de um mundo já estruturado, com um projeto inerente, cabendo a ele a completa responsabilidade pela construção de seu mundo, projeto de vida, escolhas e ações. O autor refere ainda que "a dinâmica-chave reside, então, no conflito entre nosso confronto com a falta de estrutura e nosso desejo por base e estrutura" (p.09, tradução livre da autora). A partir desse conflito, que parece estar centrado apenas no sujeito, Yalom propõe categorias psicopatológicas que estariam ligadas ao não reconhecimento dessa liberdade e da consequente responsabilidade pela própria vida, relegando a fontes externas a "causa" de seus comportamentos e modos de ser. A responsabilidade está irrevogavelmente implicada na liberdade (Yalom, 1980)

Assim como o psiquiatra norte-americano, Feijoo (2010) apresenta algumas temáticas predominantes no contexto psicoterapêutico que estariam relacionadas ao sofrimento psíquico tais como "culpa existencial", "perda no impessoal”, "projeto idealizado de si mesmo" (Feijoo, 2010, p. 132) etc.,assim como a "posição psicológica de não-liberdade", conceito retirado de Kierkegaard. Todavia, um dos pontos cruciais em Feijoo é a concepção de que tais "problemas psíquicos" não são problemas do Eu, do orgânico ou da semântica interna, mas sim problemas da relação ser-aí/mundo, do projeto existencial. Dessa forma, a autora brasileira opõe-se à lógica da interioridade e do modelo cartesiano, imperante na psicologia tradicional moderna.

Frente a tais ideias acerca do sofrimento psíquico, pode-se dizer que o propósito da psicoterapia, numa abordagem fenomenológico-existencial, é tornar o sujeito consciente de sua condição de liberdade (Feijoo, 2010; May, 1987; Yalom, 1980). O que consiste em ajudá-lo a experimentar suas possibilidades, buscando romper com o aprisionamento do ser em comportamentos sedimentados (Feijoo, 2011), resgatando sua condição de abertura.

Entretanto, a questão da liberdade é sempre um paradoxo. May (1987) defende que a liberdade perde sua fundação ao ser encarada sem seu oposto necessário que lhe dá viabilidade, o destino. Este representa, aqui, os fatores deterministas, que em momento algum são negados em sua existência: "Mas é preciso concordar que existe uma margem na qual o ser humano pode ter consciência do que o está impelindo [grifo do autor]. E, embora de maneira reduzida ao início, poderá interferir nas suas reações diante dos fatores deterministas" (May, 1982, p. 135”. Assim:

A liberdade não é ação desordenada, mas sim a capacidade de aventar possibilidades diferentes na mente, embora não esteja definido qual caminho que se deve adotar. A pessoa psicologicamente saudável é capaz de controlar a ansiedade frente às possibilidades, em contraste com o neurótico que permite que ela bloqueie a consciência de liberdade e dá a sensação de não ter escolha (May, 1987, p. 36).

É diante desta discussão que esse estudo se propõe a fazer uma revisão a partir de publicações atuais sobre a o conceito de liberdade na perspectiva das abordagens fenomenológicas e existenciais em psicologia. Como foi demonstrado anteriormente, no que se refere a clínica psicológica, por exemplo, o conceito de liberdade tem sido associado ao que entende-se por saúde e sofrimento psíquico; no entanto, parece não existir uma clareza e nem uma uniformidade conceitual e epistemológica sobre o conceito. O objetivo deste estudo, portanto, foi procurar evidenciar o estado do conhecimento desta temática, além de explorar os diversos sentidos atribuídos à liberdade e as principais questões a ela atreladas pelos autores das publicações triadas. Espera-se que as informações da presente pesquisa possibilitem a exposição de um panorama do estado de conhecimento sobre liberdade nos últimos vinte anos. Trata-se de um mapeamento do campo de produção bibliográfica que objetiva, a partir da revisão sistemática de artigos, demonstrar possíveis convergências ou divergências teóricas e conceituais que venham a auxiliar na produção de outros estudos acerca do tema.

\section{Método}

As fontes consultadas para a revisão sistemática foram as seguintes bases de dados eletrônicos: portal de periódicos da Coordenação de Aperfeiçoamento de Pessoal de Nível Superior (CAPES); Periódicos Eletrônicos em Psicologia (PePSIC); Literatura Latino-Americana e do Caribe em Ciências da Saúde (LILACS) e Scientific Electronic Library 
Online (SciELO). A escolha das fontes teve como critério a gratuidade e a disponibilidade de acesso em ambiente universitário. Os descritores foram utilizados de maneira que sempre houvesse pelo menos um termo referente à abordagem teórica e um termo referente à liberdade combinados em cada busca, sendo eles: psicologia existencial, psicologia fenomenológica, psicologia fenomenológica existencial, psicologia fenomenológica-existencial, psicologia fenomenológico existencial, psicologia fenomenológico-existencial, psicologia existencialista, liberdade. Os termos também foram utilizados em inglês, sendo eles: existential psychology, phenomenological psychology, existential phenomenological psychology, existential-phenomenological psychology, existentialist psychology, freedom. E em espanhol:"psicología existencial", "psicología fenomenológica", "psicología fenomenológica existencial", "psicología fenomenológica-existencial", "psicología fenomenológico existencial", "psicología fenomenológico-existencial", "psicología existencialista" , libertad. Os termos referentes à abordagem teórica foram escolhidos devido à verificação de variações no uso do hífen por autores, assim como a existência de tais termos nos Descritores em Ciência da Saúde (DeCS), da Biblioteca Virtual em Saúde . Desse modo, a pesquisa contou com 19 combinações de palavras-chave.

Foram utilizados critérios de inclusão referentes à delimitação temporal das publicações, ao tipo de material e aos idiomas. O tempo de publicação foi delimitado entre 1998 e $2017^{2}$, com vistas a discutir o estado de arte do conhecimento sobre o tema. Já os materiais selecionados foram apenas artigos revisados por pares, a fim de garantir a qualidade e o rigor científico das publicações utilizadas. As pesquisas das palavras-chaves aconteceram em quatro diferentes momentos $(24 / 04 / 17,15 / 05 / 17,06 / 06 / 17$ e 03/07/17) com o objetivo de garantir a inclusão de novos dados e evitar a perda de dados por motivos de falha na base eletrônica ou de conexão com a internet. Inicialmente, verificou-se variação dos resultados na base Portal de Periódicos da CAPES de acordo com a realização ou não do login de usuário no site da base, o que demandou atenção e a adoção de um critério metodológico de maneira a utilizar o

\footnotetext{
1 No portal da CAPES, foi feito o uso de aspas nos descritores em espanhol referentes à abordagem teórica, pois verificou-se que a pesquisa sem aspas resultava em um grande número de estudos não relacionados com a psicologia em geral. Logo, optou-se por essa estratégia - o uso de aspas tem o efeito de buscar estudos em que os termos de uma palavra composta apareçam necessariamente juntos - para filtrar apenas resultados com temáticas próximas à psicologia fenomenológico-existencial.

2 O período de publicação foi determinado de forma independente, a partir de buscas no portal da CAPES utilizando os descritores referentes à abordagem teórica, nos três idiomas, e filtros para artigos com data: até 1997; de 1998 a 2007; e de 2008 a 2017. O maior número de publicações foi encontrado nos períodos 1998-2007 e 2008-2017, apontando os últimos 20 anos como período de maior produção acadêmica em psicologia fenomenológico-existencial. $\mathrm{O}$ total de publicações com data até 1997 correspondeu a 4,43\% do total de publicações dos últimos 20 anos.
}

site desta base apenas com o usuário logado.

A princípio, considerou-se o número total de publicações encontradas que, após, foram sendo triadas de acordo com os critério de inclusão na seguinte ordem: apenas artigos, data da publicação de 1998 a 2017, artigos revisados por pares e idiomas. Numa segunda etapa de seleção, foi realizada a exclusão de artigos duplicados, sendo, para tal, utilizada a ferramenta online de administração de referências End Note ${ }^{\mathrm{TM}}$,da Clarivate Analytics, onde também foi avaliada a disponibilidade dos artigos, excluindo-se as publicações sem texto integral disponível. Na sequência, foi realizada a análise dos títulos, subtítulos, resumos e palavras-chave das publicações para avaliar a elegibilidade de acordo com a abordagem teórica (psicologia fenomenológico-existencial) e a proximidade com o tema da liberdade. Nesta fase, optou-se pela inclusão de apenas artigos teóricos devido ao caráter teórico-conceitual da questão de pesquisa deste estudo, visto que pesquisas empíricas não permitiriam um aprofundamento em torno do conceito de liberdade. Assim, os critérios de exclusão foram: artigos empíricos, artigos não relacionados ao tema da liberdade e artigos de outra abordagem teórica.

A seguir, foi realizada a leitura integral dos artigos para análise de variáveis quantitativas e qualitativas. As variáveis quantitativas foram: ano de publicação, nacionalidade dos artigos, área da revista, e área de formação ou de prática dos autores. Para a análise das variáveis qualitativas, optou-se pelo "método hermenêutico-dialético" (Minayo, 2010, p.327; Minayo, 2001), uma proposta de interpretação qualitativa de dados que consiste em três etapas: ordenação dos dados, através do mapeamento de todo o material encontrado no estudo; classificações dos dados, através da leitura horizontal e exaustiva dos textos para estabelecer categorias empíricas, e leitura transversal, a fim de realizar uma redução das classificações, agrupando-as em um número menor de unidades de sentido; e análise final, com a articulação entre os dados encontrados e os referenciais teóricos, com vistas a trazer à tona as significações presentes sobre determinado tema em um dado contexto. As categorias qualitativas apreciadas foram: teóricos e filósofos de base, temáticas gerais dos artigos, forma de articulação com a Psicologia, termos atrelados à liberdade e a forma como os artigos conceituam liberdade. No tocante à última categoria, pensou-se em duas unidades de análise a partir das quais o conceito de liberdade seria considerado: liberdade a que/a quem e liberdade para quê.

Ao final da análise dos estudos encontrados, foi realizada uma síntese descritiva dos achados, seguida de uma discussão reflexiva com o intuito de integrar o conhecimento atual sobre a temática aos pressupostos dos autores nos quais se baseia a psicologia fenomenológico-existencial. 


\section{Resultados}

Na seleção dos artigos, conforme metodologia descrita, foram identificados 29 artigos que atendiam aos critérios de inclusão. (Figura 1 - Fluxograma). Foi então realizada a leitura integral desses artigos a fim de identificar e analisar as variáveis quantitativas e qualitativas. No decorrer da leitura, manteve como questão norteadora da investigação o objetivo do presente estudo em evidenciar o estado do conhecimento sobre o tema da liberdade na perspectiva da psicologia fenomenológico-existencial, assim como identificar outras características relevantes atreladas à produção bibliográfica sobre o tema.

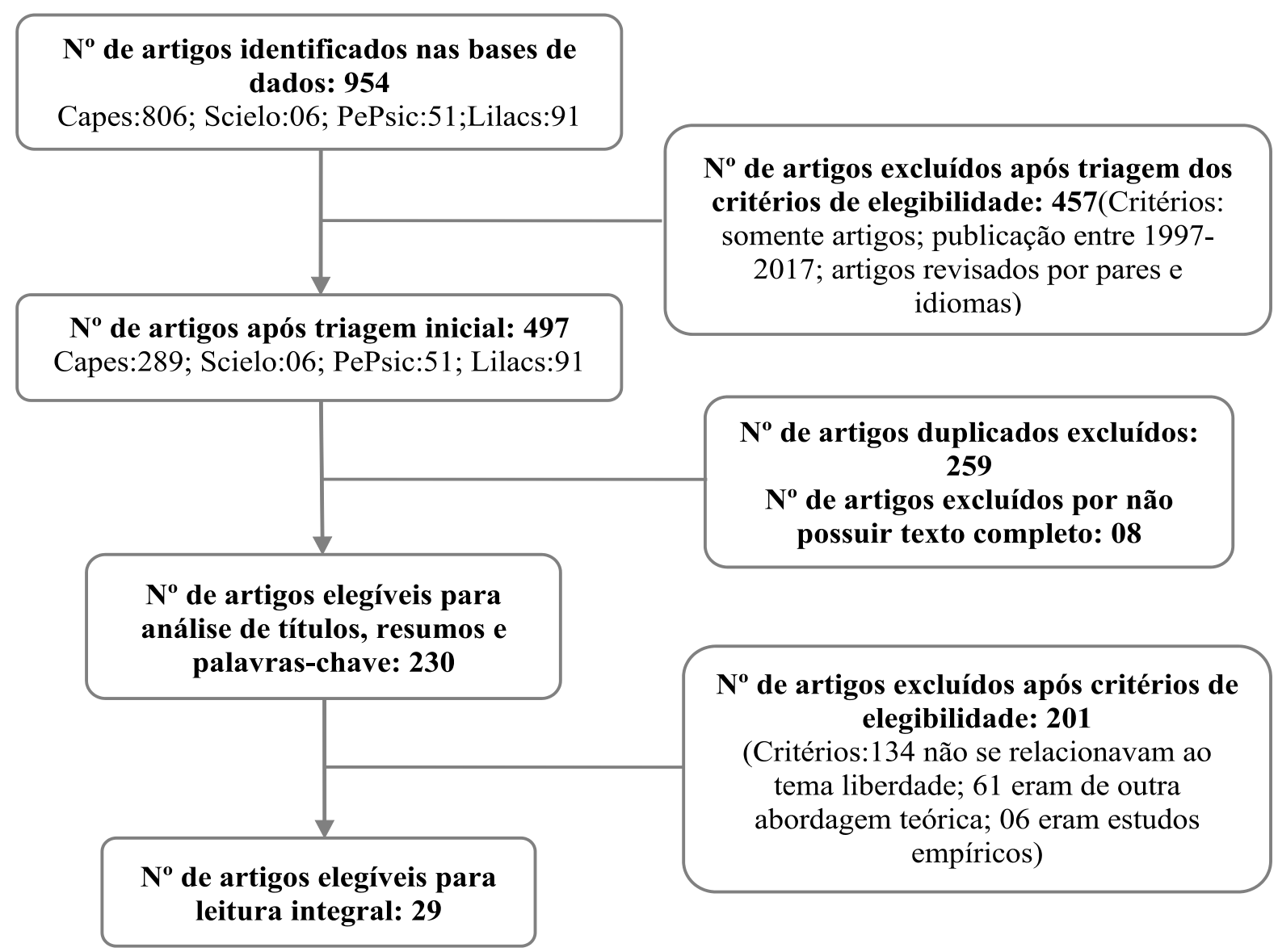

Figura 1.Fluxograma.

Quanto ao período de publicação, foram encontrados artigos publicados entre 2000 e 2016, sendo a média aritmética encontrada de 1,70 artigos por ano. Artigos publicados entre 1998-2007 corresponderam a $20,5 \%$ do total, e os publicados entre 2008-
2017 a 79,5\%. O período de maior publicação foi no ano de 2011 com sete artigos publicados, seguido de 2013 e 2015, ambos com quatro artigos publicados (Figura 2- Gráfico).

\section{Publicações/Ano}

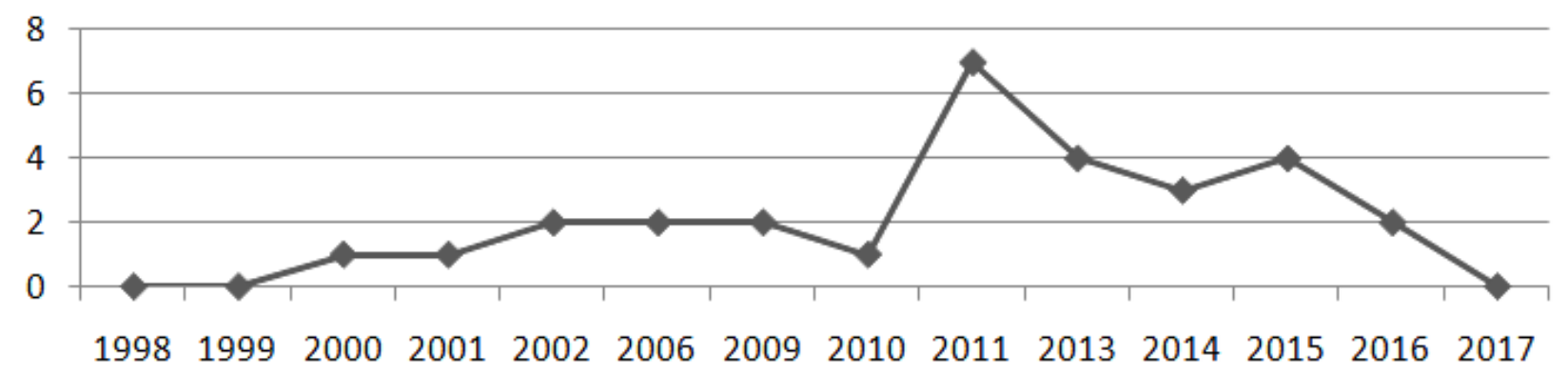

Figura 2.Gráfico. 
Na categoria nacionalidade, analisada de acordo com o vínculo institucional dos autores, predominaram artigos do Brasil, com 17 publicações (58,6\%), seguido do Reino Unido e Colômbia, ambos com três publicações $(10,4 \%)$. Também se verificou autores dos Estados Unidos da América, Holanda, Dinamarca, Grécia e Portugal. Com relação à área de especialidade das revistas, apenas dois periódicos não eram classificados como da área de conhecimento da Psicologia, sendo um direcionado à Filosofia e outro a ciências multidisciplinares. Da mesma maneira, predominaram autores com formação ou atuação em Psicologia, identificados em 26 artigos. Outros dois artigos eram de autores da Filosofia e da área de Letras.

No que tange a análise qualitativa dos resultados, um dos objetivos era a identificação dos teóricos e filósofos de base mais frequentemente citados. Observou-se a presença, principalmente de Sartre, J. P., Heidegger, M. e May, R. Outros teóricos também referenciados nos artigos foram Merleau-Ponty, M., Yalom, I. D., Husserl, E., Binswanger, L., Kierkegaard, S. A., Scheler, M., Frankl, V. E., entre outros. Quanto ao interesse de articulação dos artigos com a Psicologia, a maioria apresentou enfoque clínico (16 artigos) e epistemológico (07 artigos). Outros enfoques identificados foram: psicologia social, psicopatologia, psicologia do desenvolvimento, psicologia experimental, pesquisa em psicologia e saúde coletiva.

Outra categorização oriunda da análise qualitativa foi o agrupamento das temáticas gerais apresentadas pelos autores de forma direta e indireta. Com relação às temáticas gerais dos 29 artigos, foram identificadas 35 temáticas predominantes. Após a listagem e análise de tais temáticas, foi possível agrupá-las de acordo com a proximidade dos assuntos abordados, de maneira que foram criadas cinco subcategorias. Estas categorias são apresentadas a seguir, seguidas da frequência em que foram identificadas:a) artigos que versavam sobre aspectos da construção do ser: personalização, identidade, educação (2), desenvolvimento, incompletude, infância (2), imaginação e determinismo; b) artigos que abordavam aspectos sociológicos: historicidade, poder, cultura, comunidade, literatura (2), forças sociológicas, técnica moderna, crise epocal eengajamento (2); 3) sobre aspectos do adoecimento/sofrimento:angústia(3), sofrimento, adoecimento, psicopatologia(2), enfermidade, desespero, dependência química e loucura;c) os que abordavam o ser em relação:relacionamentos,sexualidade, ciúmes e redes digitais;d) e os que traziam questões sobre ética e dimensão espiritual:espírito,logoterapia, ética,consciência, Deus e razão.

Com relação à forma de articulação dos artigos com o campo da Psicologia, outra variável qualitativa, encontrou-se uma predominância do enfoque clínico ou do processo psicoterapêutico (16 artigos), seguida de aspectos epistemológicos da psicologia fenomenológico-existencial (07 artigos). Outras áreas da Psicologia abordadas foram: psicologia social (3), psicopatologia (2), psicologia do desenvolvimento (1), psicologia experimental (1), saúde coletiva (1) e pesquisa em psicologia (1). Na análise dos termos que se mostraram diretamente atrelados à liberdade nos textos selecionados, foram identificados 39 termos. A seguir, os termos que mais se repetiram são expostos de acordo com a freqüência em que foram identificados: angústia (8), responsabilidade (8), projeto (7), sentido (4), escolha (4), abertura (3), criação (3) e cuidado (3).

Ainda no que tange a análise qualitativa dos dados, para a compreensão dos sentidos atribuídos à liberdade, identificamos duas unidades de análise:liberdade a que/a quem, com vistas a entender quem é considerado livre ou o que é considerado livre, e liberdade para quê, a fim de elucidar em relação a o que a liberdade se refere.(Figura 3 - Sentidos da Liberdade).

Na unidade liberdade a que/a quem, verificou-se a existência de dois pontos de vista diferentes: a maior parte dos autores (24 artigos) destacaram a atribuição da liberdade ao ser, enquanto sua característica constitutiva, significada como abertura, incompletude, indeterminação, ou, em outras palavras, como um dos constituintes ontológicos da existência. Tal ideia pode ser ilustrada em trechos como "escolhemos simplesmente porque somosliberdade, esta é uma condição ontológica de nosso ser, que significa a nossa não determinação por uma natureza substancial” (Alt, Campos e Barata, 2011), e como "a liberdade não é um dispositivo da personalidade humana, ela não é de ordem psicológica, mas sim ontológica e antropológica" (Scheneider, 2006). Nestes artigos que trataram a liberdade como característica apriorística do ser, foram identificados alguns teóricos e filósofos comuns: Em ordem da freqüência (dos mais citados aos menos citados), são eles: Sartre, J. P., Heidegger, M., May, R. Merleau-Ponty, M. M., Kierkegaard, S. A., Husserl, E., Yalom, I. D. Binswanger, L., Jaspers, K., e Nietzsche, F.

Entretanto, em cinco artigos foi encontrada uma concepção diferente referente a quem ou a que a liberdade é atribuída. Os autores destes cinco artigos apresentaram a liberdade como característica de apenas uma parte do ser, nomeadamente, à vontade ou ao um núcleo interior. Alguns trechos que exemplificam essa concepção são: "Essa liberdade, portanto, não é uma liberdade de segurança, mas uma liberdade de descoberta - do 'núcleo interno', da imaginação, da esperança e do espírito do ser”" (Rountree, 2011, p.298), "o homem se confronta com três formas básicas de influência condicionante sobre sua vontade livre [...]" (Pereira, 2015, p.391)

3 Tradução livre da autora: "this freedom, then, is not a freedom of security but a freedom of discovery-of one's 'inner core', of one's imagination, hope, and spirit." 
e o uso do termo "liberdade da vontade"4 (Koole, Greenberg \& Pyszczynski, p. 213; 2006; Lehmann \& Klempe, 2015, p.478) como equivalente à liberdade.
Nestes artigos, os teóricos e filósofos citados foram: Frankl, V. E., Scheler, M.,Yalom, I. D., May, R., Tatossian, A., Rogers, C. e Maslow, A.

4 Tradução livre da autora: "freedom of will"

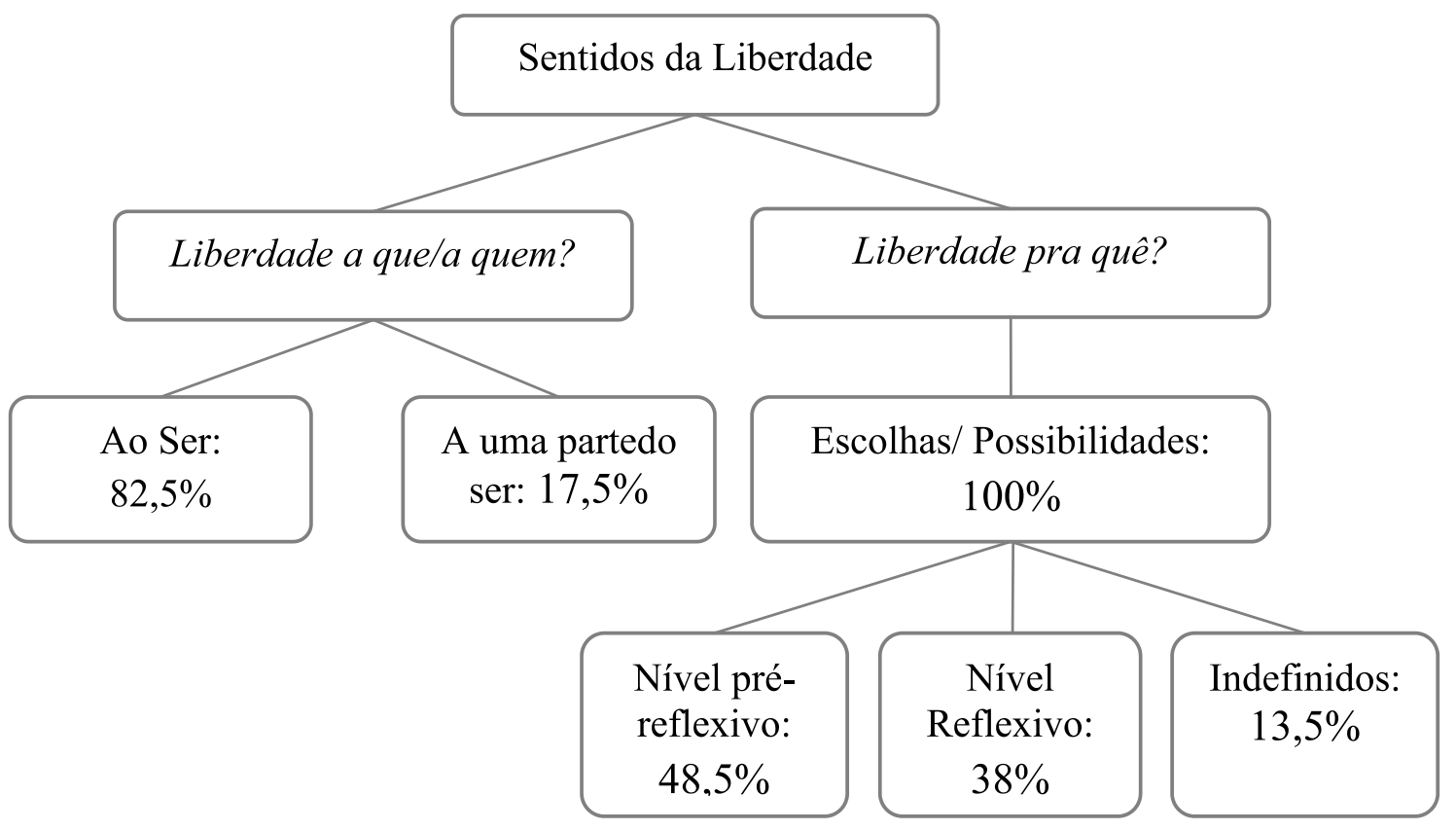

Figura 3.Sentidos da Liberdade.

O primeiro grupo (14 artigos) tratou a liberdade como escolha que se dá num nível pré-reflexivo e espontâneo, não estando em poder do ser decidir ora escolher livremente, ora não, pois a liberdade seria anterior à reflexão que possibilita uma escolha. Trechos como "a liberdade [...] é, também, a condição ontológica de possibilidade dos modos restritos da cotidianidade mediana e da angustiante ameaça de indigência radical que sempre paira sobre o existir humano” (Santos e De Sá, 2013, p.53), e “a escolha fundamental da liberdade sartreana é anterior a reflexão, é irrefletida e espontânea, constitutiva dos próprios caminhos da reflexão.”(Alt et al., 2011, p.202), exemplificam tal ideia de que a liberdade não é apenas um artifício da consciência do ser. Os teóricos e filósofos citados nestes artigos foram: Sartre, J. P., Heidegger, M., Husserl, E., Merleau-Ponty, M. M., Kierkegaard, S. A., Yalom, I. D.,May, R. Jaspers, K., e Nietzsche, F.

O segundo grupo (11 artigos), no entanto, não enfatizou tal caráter anterior da liberdade em relação à consciência, deixando margem para uma interpretação na qual as escolhas seriam advindas de uma liberdade voluntarista, onde o ser poderia escolher conscientemente ser mais livre ou menos livre. Os seguintes trechos exemplificam tal ideia: "A consciência, como a psicologia existencial-humanística claramente defende, é necessária no processo de crescimento, mudança e tornar-se livre."5(Rountree, 2011, p. 294); "trata-se da capacidade de distanciamento de sua conformação biológica e de suas determinações psíquicas; em suma, da possibilidade mesma de objetivar, conscientemente, tais imposições, e de escolher uma resposta livre frente a elas" (Pereira, 2015, pg. 391); "Desenvolver a consciência, entender nossos motivos e escolher livremente nossas respostas são atos de consciência. Atuar conscientemente e escolher livremente é o objetivo de uma vida bemvivida e plena." ${ }^{\circ}$ (Merwin, 2011, p. 30). Os teóricos e filósofos citados foram: May, R.,Sartre, J. P., Yalom, I. D.,Frankl, V. E., Scheler, M.,Merleau-Ponty, M. M.,Rogers, C. e Maslow, A.

Ainda houve um terceiro grupo (04 artigos), na unidade liberdade pra quê, quese constituiu de artigos nos quais esse aspecto não foi elucidado com clareza, ora pelo uso de ideias que se contrapunham, ora pela ausência de uma discussão sobre tal aspecto. Os teóricos e filósofos citados em tais artigos foram: Tatossian, Sartre, Heidegger, May, Yalom e Binswanger.

5 Tradução livre da autora: "Consciousness, as existential-humanistic psychology clearly advocates, is requisite in the process of growth, change, and becoming free"

6 Tradução livre da autora: "Developing awareness, understanding our motives, and freely choosing our responses are acts of consciousness. Acting consciously and choosing freely is the aim of a welllived, full life." 


\section{Discussão}

A partir da análise das 29 publicações encontradas, evidenciou-se o caráter atual da discussão acerca da liberdade em artigos de base fenomenológico-existencial, principalmente devido ao maior número de artigos publicados na última década, quando comparada à década anterior. Tal fato reforça a pertinência de uma revisão sistemática que busque compreender como a temática vem sendo tratada pelos autores desta abordagem. Os autores brasileiros destacaram-se pela predominância de artigos sobre o tema. Embora a Psicologia fosse a área de formação da maior parte dos autores dos artigos, a presença de autores de outras duas áreas fez sentido, considerando a interlocução da psicologia fenomenológico-existencial especialmente com a Filosofia, enquanto fundamentação epistemológica, mas também com a Literatura, através de Sartre.

A angústia e a responsabilidade foram os termos mais atrelados ao conceito de liberdade pelos autores. Concisamente representada nas palavras de Ponte (2013, p.61), “as possibilidades disponíveis ao humano, suas aberturas existenciais propiciadoras do poder-escolher, exercício de sua destinação no devir temporal fático, parecem configurar-se como o que há de mais opressor, estrangulador; numa palavra, angustiante.” Tal achado parece ecoar as ideias de Boss (1981) acerca da angústia enquanto dimensão constitutiva do ser, ao deparar-se com o Nada no qual reside sua liberdade. Ou, ainda, a angústia da qual fala Yalom (1980) frente à falta de estrutura oferecida ao ser perante o mundo, o que demanda que ele construa seu próprio projeto de existência, sob sua total responsabilidade. De modo geral, a maior parte dos termos atrelados à liberdade retomam os teóricos e filósofos precursores da psicologia fenomenológico-existencial e autores contemporâneos que exercem impacto na área

Dados importantes emergiram da análise da forma como a liberdade foi conceituada. . Pode-se afirmar que, nas produções de base fenomenológico-existencial, a liberdade é tratada como uma característica fundamental do ser humano, perspectiva que não encontramos em outros sistemas teóricos da psicologia. Entretanto, esta conceituação de liberdade, como característica fundamental do ser, expressa dois enfoques diferentes. Primeiramente, na unidade de análise liberdade a que/a quem, houve a predominância $(82,5 \%)$ da atribuição da liberdade ao ser enquanto sua característica ontológica,ou seja, à indeterminação do ser. Já 17,5\% dos autores descreveram a liberdade enquanto característica de uma parte do ser, como a vontade ou a um núcleo interior.

Analisando os teóricos e filósofos de base desses artigos, cabe ressaltar que, no segundo grupo, preponderaram teóricos da Psicologia de base humanista, como Rogers e Maslow, assim como May e Yalom, considerados humanistas-existenciais (Teixeira, 2006; Ponte \& Souza, 2011). Enquanto que no primeiro grupo, os teóricos e filósofos mais citados foram Sartre, Heidegger, Kierkegaard e May, sendo os três primeiros considerados por Feijoo (2011) os filósofos mais discutidos na psicologia fenomenológico-existencial.

Dessa forma, considera-se que o embasamento em teóricos com influências humanistas implica na diferença de sentidos atribuídos à liberdade e ao ser, devido às diferenças presentes nas noções de sujeito da psicologia humanista e da psicologia fenomeonológico-existencial. Além disso, o uso do conceito de liberdade nos artigos com base humanista ou humanista-existencial foi atrelado a conceitos contrários ao escopo da psicologia fenomenológico-existencial, como por exemplo, a ideia de potencialidade (Bloc \& Moreira, 2013), de crescimento interior (Koole et al., 2006), de pessoa interior e de atualização (Rountree, 2011). O uso de tais termos implica em concepções valorativas acerca da liberdade, como um artifício de potencialidade do ser, o qual precisa tornar-se consciente do mesmo como um pré-requisito para uma vida saudável: "Agir conscientemente e escolher livremente é o objetivo de uma vida bem vivida e plena"7 (Merwin, 2011, p. 30). Tal conotação positiva da liberdade também foi encontrada em artigos baseados em Frankl e Scheler (Pereira, 2015; Lehmann \& Kemple, 2015) onde versavam sobre Logoterapia.

Assim, compreende-se que a concepção da liberdade apresentada pelos autores, na primeira unidade de análise, confronta-se com a multiplicidade e heterogeneidade das abordagens em psicologia fenomeonológico-existencial. No entanto, tais concepções parecem corresponder de forma relativamente rigorosa às fontes teóricas e filosóficas adotadas pelos autores.

Na segunda unidade de análise, liberdade para quê, todos os artigos apresentaram a temática da liberdade aliada ao sentido de ser livre para escolher, enquanto possibilidades diante das limitações, ao invés do sentido do senso comum de ser livre de algo, como livre de imposições ou limitações. Contudo, outra diferença de enfoque foi identificada quando os autores versaram sobre as escolhas. Verificou-se que $48,5 \%$ dos artigos enfatizaram a liberdade no caráter pré-reflexivo e espontâneo das escolhas, enquanto que $38 \%$ apresentaram as escolhas como livres apenas quando tomadas conscientemente, ou seja, num nível reflexivo. Neste ponto, foi identificada uma contradição, pois se esperava que apenas os autores que consideraram a liberdade como característica de uma parte do ser, na unidade liberdade a que/a quem, apresentassem a ideia de escolhas livres como um artifício da consciência ou, ainda, da vontade.

Analisando os teóricos e filósofos citados nos artigos, houve semelhança com os achados da primeira unidade de análise. O primeiro grupo, que enfatizou a liberdade no caráter pré-reflexivo e es-

7 Tradução livre da autora: "acting consciously and choosing freely is the aim of a well-lived, full life." 
pontâneo das escolhas, citou, principalmente, filósofos (Sartre, Heidegger, Husserl, Merleau-Ponty e Kierkegaard), enquanto que o segundo grupo, que enfatizou as escolhas como livres apenas quando tomadas conscientemente de forma reflexiva, fez referência com mais predominância a teóricos da psicologia (May, Yalom, Frankl, Rogers e Maslow), bem como a Sartre. A diferença, aqui, está na inclusão de artigos baseados em Sartre que, na primeira unidade, consideraram a liberdade como condição do ser, ao passo que na segunda unidade, versaram sobre escolhas livres como escolhas conscientes. Há um aspecto controverso nestes artigos, o que pode significar que os autores omitiram a ênfase no caráter pré-reflexivo e espontâneo da liberdade, pois isto estaria implícito na descrição da liberdade enquanto condição do ser. Ou ainda pode indicar que os autores não foram fiéis aos pressupostos de Sartre sobre liberdade:

O homem é livre porque não é si mesmo, mas presença a si. O ser que é o que é não poderia ser livre. A liberdade é precisamente o nada que é tendo sidono âmago do homem e obriga a realidade-humana a fazer-seem vez deser(...) para a realidade-humana ser é escolher-se (Sartre como citado em Alt et al., 2011, p. 202).

Outro aspecto que se sobressaltou na unidade liberdade para quê diz respeito à nacionalidade dos autores. No primeiro grupo, que apontou a liberdade de escolha como pré-reflexiva, encontrou-se apenas autores brasileiros e um autor português, ao passo que no grupo que trouxe a liberdade como ação reflexiva ou voluntarista, verificaram-se autores das demais nacionalidades citadas na sessão anterior, inclusive a brasileira, embora em menor número (dois artigos). Considerando a análise dos teóricos e filósofos feita acima, tal achado ressalta a presença de coesão na produção nacional. Isto pode indicar que estudiosos brasileiros dessa abordagem estão mais preocupados em retornar às fontes da filosofia nas quais está fundamentada epistemologicamente a psicologia fenomenológico-existencial.

Tendo em vista que mais da metade dos 29 artigos selecionados apresentaram um enfoque em psicologia clínica, também emergiram considerações sobre a relação da liberdade com o sofrimento ou adoecimento psíquico. De maneira geral, os autores baseados na abordagem fenomenológico-existencial argumentam que o adoecimento está relacionado à dificuldade do ser em suportar a angústia proveniente de sua condição de abertura com os sentidos do mundo. De forma que o ser se fecha a determinadas formas de existência, que muitas vezes correspondem às categorias nosológicas de psicopatologia, porém nunca perdendo sua condição de liberdade. Assim, tanto "ser doente" como "ser saudável" são tratados como possibilidades de modos de ser:
Os fenômenos de adoecimento psíquico se vinculam, portanto, à própria condição de abertura do Dasein; consistem na sua identificação a certas possibilidades de ser, em detrimento de outras, constituindo cenários existenciais restritos que têm por fundamento de possibilidade sua condição originária de liberdade (Magliano \& Sá, 2015, p. 28)

\section{Considerações Finais}

Por fim, cabe ressaltar que, mesmo que se tenham seguido os cuidados metodológicos, este estudo está sujeito a limitações. Primeiramente, o uso de quatro bases de dados eletrônicos nacionais e gratuitas, levando a não abrangência da produção bibliográfica de bases privadas e internacionais. Esta limitação pode, estar relacionada à identificação mais predominante de artigos brasileiros. Há, ainda, a possibilidade de perda de dados na etapa de análise de elegibilidade dos artigos, pelo fato desta restringir-se à leitura dos resumos e palavras-chave. Também, considera-se que a eleição das variáveis qualitativas implique diretamente no tipo de resultados obtidos, de forma que a inclusão de outras variáveis ou mesmo o uso de um conjunto diferente de variáveis poderia proporcionar discussões sobre outros aspectos da liberdade que não foram abordados neste estudo.

Considerou-se que a temática da liberdade abre um amplo campo de possibilidades teóricas e reflexivas na perspectiva da psicologia fenomenológico-existencial. Este estudo proporcionou, ainda que de maneira preliminar, a exposição de um panorama do estado de conhecimento sobre liberdade, a partir dos artigos elegidos nos últimos 20 anos. Esperou-se, assim, que as informações da presente pesquisa possibilitem outras produções bibliográficas acerca do tema e contribuam para a consolidação teórica no campo da psicologia fenomenológico-existencial.

\section{Referências}

Alt,F.,Campos,C.M.\&Barata,A...(2011).Dificuldades, desafios e possibilidades para uma clínica Sartreana. Revista da Abordagem Gestáltica, 17(2), 198-204. Recuperado em 26 de Junho de 2017, de http://pepsic.bvsalud.org/scielo.php?script=sci_arttext\&pi$\mathrm{d}=$ S1809-68672011000200011\&lng $=\mathrm{pt} \& \operatorname{lng}=\overline{\mathrm{pt}}$.

Bloc, L., \& Moreira, V. (2013). Sintoma e fenômeno na psicopatologia fenomenológica de Arthur Tatossian. Revista Latinoamericana de Psicopatologia Fundamental, 16(1), 28-41. Recuperado em 26 de Junho de 2017, de https://dx.doi. org/10.1590/S1415-47142013000100003

Boss, M. (1981). Angústia, culpa e libertação. São Paulo: Livraria Duas Cidades. 
Castro, A. L. de S. \& Guareschi, P. (2008). Da privação da dignidade social à privação da liberdade individual. Psicologia \& Sociedade, 20(2), 200-207. Recuperado em 13 de Junho, 2017, de https:/dx.doi.org/10.1590/S010271822008000200007

Castro, A. M. F. de M. \& Teodoro, M. L. M. (2014). Relações familiares de adolescentes cumprindo medida socioeducativa restritiva de liberdade: uma revisão narrativa da literatura. Temas em Psicologia, 22(1), 01-12. Recuperado em 13 de Junho, 2017, de https://dx.doi.org/10.9788/TP2014.1-01

Feijoo, A. M. L. C. (2010). A escuta e a fala em psicoterapia: uma proposta

fenomenológico-existencial (2a ed.). Rio de Janeiro: Edições IFEN.

Feijoo, A. M. L. C. (2011). A existência para além do sujeito: A crise da subjetividade moderna e suas repercussões para a possibilidade de uma clínica psicológica com fundamentos fenomenológico-existenciais. Rio de Janeiro: Edições IFEN: Via Verita.

Gomes, W. B., \& Castro, T. G. D. (2010). Clínica fenomenológica: do método de pesquisa para a prática psicoterapêutica. Psicologia: Teoria e Pesquisa,26(25ANOS), 81-94. Recuperado em 13 de Junho, 2017, de https://dx.doi.org/10.1590/ $\underline{\text { S0102-37722010000500007 }}$

Gomes, C. C. \& Conceição, M. I. G. (2014). Sentidos da trajetória de vida para adolescentes em medida de liberdade assistida. Psicologia em Estudo, 19(1), 47-58. Recuperado em 13 de Junho, 2017, de https://dx.doi.org/10.1590/1413-7372189590005

Koole, S. L., Greenberg, J., \& Pyszczynski, T. (2006). Introducing science to the psychology of the soul: Experimental existential psychology. Current Directions in Psychological Science, 15(5), 212-216. Retrieved June 13, 2017 from http:// journals.sagepub.com/doi/abs/10.1111/j. 1467-8721.2006.00438.x

Lehmann, O. V. \& Klempe, S. H. (2015). Psychology and the Notion of the Spirit: Implications of Max Scheler's Anthropological Philosophy in Theory of Psychology.Integr Psychol Behav Sci. 49(3):478-84. Retrieved June 13, 2017 from doi: 10.1007/s12124-015-9295-5.

Magliano F. da R. \& Sá, R. N. de. (2015). Reflexões heideggerianas sobre técnica, liberdade e práticas psicológicas clínicas. Arquivos Brasileiros de Psicologia, 67(2), 19-32. Recuperado em 01 de Agosto de 2017, de http://pepsic.bvsalud.org/scielo.php?script $=$ sci_arttext\&pi$\mathrm{d}=$ S1809-52672015000200003\&lng $=$ pt\&tlng $=\overline{\text { pt }}$.
Marques, E. T. \& Ribeiro, J. L. P. (2013). Comportamentos (a) normais e recurso à entrevista estruturada na avaliação de (in)imputáveis juridicamente privados de liberdade. Psicologia: Ciência e Profissão, 33(3), 564-579. Recuperado em 13 de Junho, 2017, de https://dx.doi. org/10.1590/S1414-98932013000300005

May, R. (1982). Homem à procura de si mesmo. Petrópolis: Vozes.

May, R. (1987). Liberdade e destino. Rio de Janeiro: Rocco.

Merwin, M. M. (2011). Lessons From an Existentialist: What Rollo May Taught Me About Power in the Classroom. Journal of Humanistic Psychology, 51(1), 28-40. Retrieved June 13, 2017, from http://journals.sagepub.com/ doi/abs/10.1177/0022167809360260?journalCode $=$ jhpa

Minayo, M. C. de S. (org.). (2001). Pesquisa Social. Teoria, método e criatividade. (18 ed.) Petrópolis: Vozes

Minayo, M. C. de S. (2010). O desafio do conhecimento: pesquisa qualitativa em saúde. (12 ed.). São Paulo: Hucitec

Moreira, V. (2011). A contribuição de Jaspers, Binswanger, Boss e Tatossian para a psicopatologia fenomenológica. Revista da Abordagem Gestáltica,17(2), 172184. Recuperado em 13 de Junho, 2017, de http://pepsic.bvsalud.org/scielo.php?script=sci_arttext\&pi$\mathrm{d}=$ S1809-68672011000200008\&lng $=$ pt\&tlng $=$ pt.

Pereira, I. S. (2015). Espírito e liberdade na obra de Viktor Frankl. Psicologia USP, 26(3), 390396. Recuperado em 13 de Junho, 2017, de https://dx.doi.org/10.1590/0103-656420140036

Ponte, C. R. S. da. (2013). Reflexões sobre a angústia em Rollo May. Revista do NUFEN, 5(1), 4556. Recuperado em 26 de Junho de 2017, de http://pepsic.bvsalud.org/scielo.php?script=sci_arttext\&pi$\mathrm{d}=$ S2175-25912013000100007\&lng $=$ pt\&tlng $=$ pt.

Ponte, C. R. S. da, \& Sousa, H. L. de. (2011). Reflexões críticas acerca da psicologia existencial de Rollo May. Revista da Abordagem Gestáltica, 17(1), 47-58. Recuperado em 26 de Agosto de 2017, de http://pepsic.bvsalud.org/scielo.php?script=sci_arttext\&pi$\mathrm{d}=$ S1809-68672011000100008\&lng $=$ pt\&tlng $=\overline{\text { pt }}$.

Rountree, J. (2011). Joining Inner and Outer Approaches to Freedom: Meeting the Needs of Developing Communities. Journal of Humanistic Psychology. 51. 291-317. Retrieved June 13, 2017 from 10.1177/0022167810382453. 
Santos, D. de G. \& Sá, R. N. de. (2013). A existência como "cuidado": elaborações fenomenológicas sobre a psicoterapia na contemporaneidade. Revista da Abordagem Gestáltica, 19(1), 53-59. Recuperado em 26 de Junho de 2017, de http://pepsic.bvsalud.org/scielo.php?script=sci_arttext\&pi$\mathrm{d}=$ S1809-68672013000100007\&lng $=$ pt\&tlng $=$ pt.

Schneider, D. R.. (2006). Liberdade e dinâmica psicológica em Sartre. Natureza humana , 8(2), 283314. Recuperado em 26 de Junho de 2017, de http://pepsic.bvsalud.org/scielo.php?script=sci_arttext\&pi$\mathrm{d}=$ S1517-24302006000200002\&lng $=$ pt\&tlng $=$ pt.

Teixeira, J. A. C. (2006). Introdução à psicoterapia existencial. Análise Psicológica, 24(3), 289-309. Recuperado em 13 de Junho, 2017, de http:// publicacoes.ispa.pt/publicacoes/index.php/ap/ article/view/169

Yalom, I. D. (1980). Existential psychotherapy (Vol. 1). New York: Basic books.

Zappe, Jana Gonçalves, Santos, Cristiane Rosa dos, Ferrão, Iara da Silva, \& Dias, Ana Cristina Garcia. (2013). Vulnerabilidade e autonomia na pesquisa com adolescentes privados de liberdade. Psicologia: Ciência e Profissão, 33(1), 234-247. Recuperado em 13 de Junho, 2017, de https:// dx.doi.org/10.1590/S1414-98932013000100018
Tamara Endrissi (orcid.org/0000-0002-6559-6023). Psicóloga graduada pela Universidade Federal de Ciências da Saúde de Porto Alegre - UFCSPA. Email: tamaraendrissi@gmail.com

Lucia Marques Stenzel (orcid.org/0000-00032040-1998). Doutora em Psicologia pela Pontifícia Universidade Católica do Rio Grande do Sul (PUCRS). Professora Associada do Departamento de Psicologia na Universidade Federal de Ciências da Saúde de Porto Alegre (UFCSPA). Professora do Programa de Pós-Graduação em Psicologia e Saúde (UFCSPA). Endereço Institucional: Rua Sarmento Leite, 245 sala 207 - Porto Alegre/RS CEP:90050170. Email: lstenzel@ufcspa.edu.br

Recebido em 26.01.2018 Primeira Decisão Editorial em 03.04.2019 Segunda Decisão Editorial em 02.09.2019 Aceito em 14.12.2019 